\title{
Lanthanoid Coordination with a Tetrazole-Substituted Calix[4]diquinone and Calix[4]dihydroquinone
}

Lee Cameron, ${ }^{\text {a }}$ Aswin Rajagopalan, ${ }^{a}$ Laura Abad Galan, ${ }^{a}$ Rene Z.H. Phe, ${ }^{a}$ Brian W. Skelton, ${ }^{\text {b }}$ Massimiliano Massi, ${ }^{\text {a }}$ and Mark I. Ogden ${ }^{\mathrm{a},{ }^{*}}$

${ }^{a}$ Curtin Institute for Functional Molecules and Interfaces, School of Molecular and Life Science, Curtin University, GPO Box U 1987, Western Australia 6845

${ }^{\mathrm{b}}$ Chemistry M313, School of Biomedical, Biomolecular and Chemical Sciences, University of Western Australia, Crawley, Western Australia 6009

email: m.ogden@curtin.edu.au

url: http://chemistry.curtin.edu.au

\begin{abstract}
The tetrazole-functionalised calixdiquinone 5,17-di-tert-butyl-26,28-bis-(tetrazol-5-ylmethoxy)calix[4]-25,27-diquinone $\mathbf{Q}$ was synthesised by chemical oxidation of the bis-tetrazole calix[4]arene precursor using $\mathrm{PbO}_{2} / \mathrm{HClO}_{4}$. The single crystal X-ray structure determination of $\mathbf{Q}$ confirmed the structure and showed binding of a water molecule in the solid state. Chemical reduction of $\mathbf{Q}$ to the dihydroquinone QR was achieved using N,N-diethylhydroxylamine. Comparison of the solution phase photophysical properties of $\mathbf{Q}$ or $\mathbf{Q R}$ in the presence of terbium ions showed significant excitation only with $\mathbf{Q R}$, suggesting redox switching of the photophysical response may be possible with this or similar receptors.
\end{abstract}

Keywords: calixarene, lanthanide, quinone 


\section{Introduction}

Calix $[n]$ quinones are oxidised derivatives of calix $[n]$ arenes where the phenol groups in the calix $[n]$ arenes are oxidised to quinones. These macrocycles have attracted interest due to their capacity to act as ionophores, combined with useful electrochemical properties, and readily accessible further functionalisation. ${ }^{1-11}$ Calix[4]quinones have previously been synthesised from the oxidation of calix[4]arenes with thallium reagents, such as thallium trifluoroacetate. ${ }^{7}$ Thallium reagents are extremely toxic, ${ }^{12}$ so there has been interest in developing alternative oxidation methodologies. For example, another synthetic pathway reported for the oxidation of calix[4]arenes uses aqueous $\mathrm{ClO}_{2} \cdot{ }^{13}$ This method, however, can only be applied to debutylated calix[4]arenes. An alternative method reported for the synthesis of calix[4]quinones from $p$-t-butylcalixarenes is oxidation with $\mathrm{PbO}_{2} / \mathrm{HClO}_{4}$, which has been reported to give similar yields to the thallium trifluoroacetate oxidation method. ${ }^{14}$ Calix[4]quinone synthesis has also been reported through electrochemical oxidation. ${ }^{1}$ This method does not require chemical oxidising reagents, but can be more difficult to scale up.

Here, we have selected the $\mathrm{PbO}_{2} / \mathrm{HClO}_{4}$ oxidation to synthesise 5,17-di-tert-butyl-26,28-bis(tetrazol-5-ylmethoxy)-calix[4]-25,27-diquinone $\mathbf{Q}$. We also report the synthesis of the reduced analogue, 5,17-di-tert-butyl-11,23,25,27-tetrahydroxy-26,28-bis-(tetrazole-5-ylmethoxy)calix[4]arene QR (Figure 1). The aim of the work was to compare the photophysical properties of lanthanoid complexes of these receptors, to determine if a redox-switchable light-emitting system could be developed.

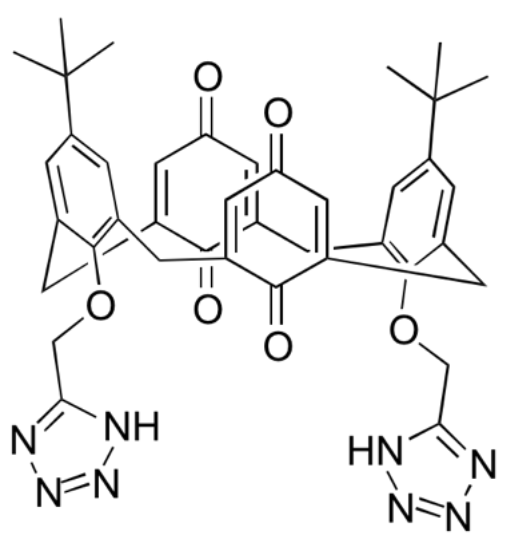

Q
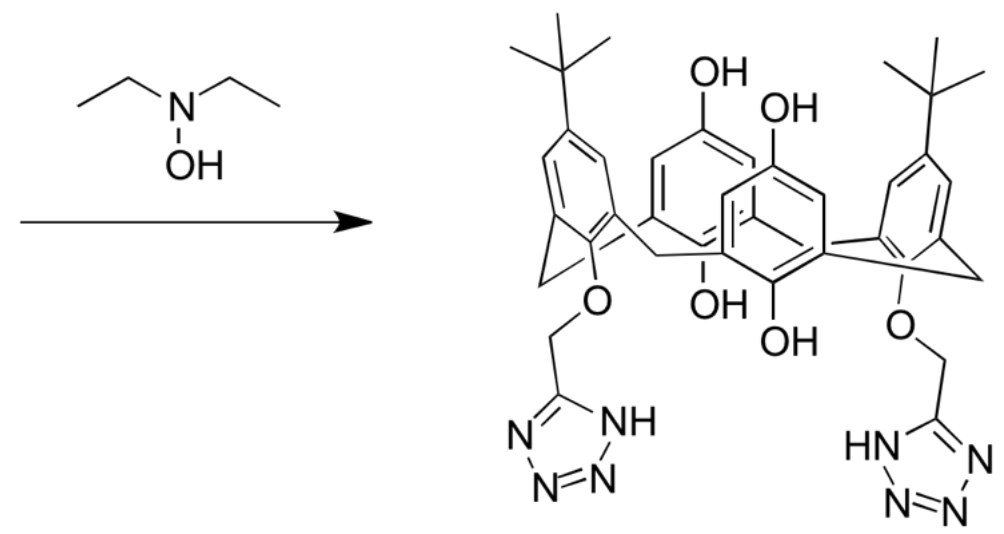

QR

Figure 1. Structures of the targeted calixarene receptors.

\section{Experimental}

All chemical reagents and solvents were purchased from Sigma-Aldrich. The 5,11,17,23-tetra-tertbutyl-25,27-dihydroxy-26,28-ditetrazolylcalix[4]arene was synthesised following the literature method. ${ }^{15}$ Melting points were recorded on a VWR-IA9100 instrument using open ended capillaries. Infrared spectra (IR) were collected using FTIR-ATR, on a Perkin-Elmer Spectrum TwoTM Infrared 
Spectrometer. Nuclear Magnetic Resonance spectra were obtained using a Bruker Ultrashield 400TM instrument $(400 \mathrm{MHz})$ at room temperature. Chemical shifts were recorded on the $\delta$ scale relative to the deuterated solvent $\left(\mathrm{CD}_{3} \mathrm{CN}\right)$. High resolution mass spectrometry was performed using a $\mathrm{Q}$ Exactive $^{\mathrm{TM}}$ Focus Hybrid Quadrupole-Orbitrap ${ }^{\mathrm{TM}}$ Mass Spectrometer from Thermo Fisher (Thermo Fisher Scientific Corporation, US).

\section{Synthesis}

\section{5,17-Di-tert-butyl-26,28-bis-(tetrazole-5-ylmethoxy)-calix[4]-25,27-diquinone (Q)}

The method was adapted from the literature. ${ }^{14}$ Lead oxide $(0.346 \mathrm{~g}, 1.49 \mathrm{mmol})$, and perchloric acid $(1 \mathrm{~mL}, 11.6 \mathrm{mmol})$ were added to a dichloromethane:acetone mixture $(8 \mathrm{~mL}, 1: 1)$ and stirred. A solution of 5,11,17,23-tetra-tert-butyl-25,27-dihydroxy-26,28-ditetrazolylcalix[4]arene (0.229 g, $0.282 \mathrm{mmol})$ in dichloromethane $(2 \mathrm{~mL})$, and acetone $(2 \mathrm{~mL})$ was slowly added dropwise to the lead solution. The mixture was stirred for 2 hours at room temperature, then filtered through celite, washing all the yellow solution through with dichloromethane $(20 \mathrm{~mL})$. Filtrate was washed with water $(2 \times 20 \mathrm{~mL})$, collecting the organic phase which was dried over magnesium sulphate. Solvent was removed under reduced pressure, yielding yellow crystals. The crude product was sonicated in acetone $(9 \mathrm{~mL})$ for 15 minutes, before undergoing centrifugation $(6500 \mathrm{rpm}, 5 \mathrm{~min})$ three times, replacing the supernatant acetone each time, before removing excess solvent, yielding bright yellow crystals. Yield: $50 \mathrm{mg}(25 \%)$ Crystal of appropriate quality for a single crystal structure determination were grown by slow evaporation of a methanol solution.

M.p.: Decomposes at $175^{\circ} \mathrm{C}$. ATR-FTIR $\left(\mathrm{cm}^{-1}\right): 3543.76 \mathrm{~cm}^{-1}\left(\mathrm{~m}\right.$, amine N-H), $2957.58 \mathrm{~cm}^{-1}(\mathrm{~m}$, alkane $\mathrm{C}-\mathrm{H}), 1658.58 \mathrm{~cm}^{-1}$ (s, ketone $\left.\mathrm{C}=\mathrm{O}\right), 1482.68 \mathrm{~cm}^{-1}(\mathrm{~m}$, aromatic $\mathrm{C}=\mathrm{C}), 1197.05 \mathrm{~cm}^{-1}(\mathrm{~m}$, ether C-O). ${ }^{1} \mathrm{H}$ NMR (400 MHz, CD $\mathrm{CNN}$ ) 7.12 (s, 4H), 6.63 (s, 4H), 5.27 (s, 4H), 3.79 (d, J=14.2 Hz, $4 \mathrm{H}), 3.34$ (d, $J=14.4 \mathrm{~Hz}, 4 \mathrm{H}), 1.20$ (s, 18H). ${ }^{13} \mathrm{C}$ NMR $\left(\mathrm{CD}_{3} \mathrm{CN}\right): \delta(\mathrm{ppm}) 207.48,188.45,187.23$, 152.25, 149.26, 148.88, 133.58, 131.76, 128.47, 64.92, 35.04, 32.93, 31.54. HRMS (ESI/Q-TOF) $\mathrm{m} / \mathrm{z}:[\mathrm{M}+\mathrm{H}]^{+}$Calcd for $\mathrm{C}_{40} \mathrm{H}_{41} \mathrm{~N}_{8} \mathrm{O}_{6} 729.3144$; Found 729.3135

\section{5,17-Di-tert-butyl-11,23-dihydroxy-26,28-bis-(tetrazole-5-ylmethoxy)-calix[4]-25,27- dihydroxy (QR)}

The reduction of the quinone was achieved following a modified literature procedure ${ }^{16}$ where a solution of N,N-diethylhydroxylamine (DEH) $(2.4 \mathrm{mg}, 0.027 \mathrm{mmol})$ was added into a solution of $\mathbf{Q}$ $(20 \mathrm{mg}, 0.027 \mathrm{mmol})$ in acetonitrile $(7 \mathrm{~mL})$ and stirred at room temperature for one hour. The resulting solution was neutralized with $\mathrm{HCl}(\mathrm{ca} .1 \mathrm{M})$ and washed with water. The acetonitrile layer was then 
dried under reduced pressure and the resulting product recrystallized from a mixture of acetonitrile/diethylether in $68 \%$ yield.

M.p.: $208-210^{\circ} \mathrm{C}$. ATR-FTIR ( $\left.\mathrm{cm}^{-1}\right): 3544.83 \mathrm{~cm}-1$ (m, amine N-H), 3035.68 (s, hydroxyl O-H), $2954.12 \mathrm{~cm}-1$ (m, alkane C-H), $1603.01 \mathrm{~cm}-1$ (m, hydroxyl C-O), $1463.84 \mathrm{~cm}-1$ (s, aromatic C=C), $1188.92 \mathrm{~cm}-1$ (s, ether C-O). ${ }^{1} \mathrm{H}$ NMR (400 MHz, CD $\left.{ }_{3} \mathrm{CN}\right) \delta 7.22$ (s, 4H), $6.56(\mathrm{~s}, 4 \mathrm{H}), 5.49$ (s, 4H), $4.14(\mathrm{~d}, J=12.8 \mathrm{~Hz}, 4 \mathrm{H}), 3.31(\mathrm{~d}, 4 \mathrm{H}, J=12.8 \mathrm{~Hz}, 4 \mathrm{H}), 1.21(\mathrm{~s}, 18 \mathrm{H}) .{ }^{13} \mathrm{C} \mathrm{NMR}\left(\mathrm{CD}_{3} \mathrm{CN}\right): \delta(\mathrm{ppm})$ $\delta 151.44,151.15,150.04,145.14,134.62,130.87,127.35,115.81,68.14,35.08,32.25,31.46$. HRMS (ESI/Q-TOF) m/z: $[\mathrm{M}+\mathrm{H}]^{+}$Calcd for $\mathrm{C}_{40} \mathrm{H}_{45} \mathrm{~N}_{8} \mathrm{O}_{6}$ : 733.3457. Found: 733.3448

\section{Structure Determinations}

The crystal data for $\mathbf{Q} \cdot \mathrm{H}_{2} \mathrm{O}$ are summarised below. Crystallographic data for the structure were collected at $100(2) \mathrm{K}$ on an Oxford Diffraction Gemini diffractometer using $\mathrm{Cu} \mathrm{K} \alpha$ radiation. Following multi-scan absorption corrections and solution by direct methods, the structure was refined against $F^{2}$ with full-matrix least-squares using the program SHELXL-2014. ${ }^{17}$ Both tert-butyl groups were modelled as being disordered over two sets of sites with occupancies constrained to 0.5 after trial refinement. Geometries of the disordered atoms were also restrained to ideal values. Water molecule hydrogen atoms were included and refined with geometries restrained to ideal values. All remaining hydrogen atoms were added at calculated positions and refined by use of riding models with isotropic displacement parameters based on those of the parent atoms. Anisotropic displacement parameters were employed throughout for the non-hydrogen atoms.

Q. $\mathrm{H}_{2} \mathrm{O} M=746.81$, yellow plate, $0.385 \times 0.230 \times 0.091 \mathrm{~mm}^{3}$, triclinic, space group $P \overline{1}$ (No. 2$), a=$ 9.4048(3), $b=12.2576(4), c=19.5606(6) \AA, \alpha=81.938(3), \beta=82.569(2), \gamma=89.892(2)^{\circ}, V=$ 2213.61(12) $\AA^{3}, Z=2, D_{\mathrm{c}}=1.120 \mathrm{~g} \mathrm{~cm}^{-3}, \mu=0.645 \mathrm{~mm}^{-1} . F_{000}=788,2 \theta_{\max }=67.32^{\circ}, 44939$ reflections collected, 7895 unique $\left(R_{\text {int }}=0.0417\right)$. Final $G o o F=1.095, R 1=0.1036, w R 2=0.2477$, $R$ indices based on 6942 reflections with $I>2 \sigma(I)$ (refinement on $\left.F^{2}\right),|\Delta \rho|_{\max }=0.512$ e $\AA^{-3}, 562$ parameters, 15 restraints. CCDC 1894231

\section{Supplementary material}

Full details of the structure determinations for $\mathbf{Q}$ have been deposited with the Cambridge Crystallographic Data Centre as CCDC 1894231. These data can be obtained free of charge via http://www.ccdc.cam.ac.uk/conts/retrieving.html, or from the Cambridge Crystallographic Data Centre, 12 Union Road, Cambridge CB2 1EZ, UK; fax: (+44) 1223-336-033; or e-mail: deposit@ccdc.cam.ac.uk. 


\section{Results and Discussion}

\section{Ligand Synthesis and Characterization}

The aim of this work was to develop an antenna ligand for lanthanoids that could be electrochemically switched on and off. Calixquinones were attractive electrochemically-active targets to achieve this, as they are readily synthesised, and have been studied as ionophores, for metal ions, ${ }^{4-7}$ and ion pairs. ${ }^{3,}$ ${ }^{8,9}$ To develop the proof of principle, the aim here was to synthesise the oxidised and reduced forms of the ligand, which could then be complexed independently to the relevant lanthanoid cation. The bis-tetrazole substituted calix[4]arene was selected as a starting material, based on the previously reported use of this ligand as an antenna, where lanthanoid cations were found to be coordinated to the four phenol $\mathrm{O}$ atoms, and two tetrazole $\mathrm{N}$ atoms in the solid state. ${ }^{15}$ The synthesis of the oxidised bisquinone $\mathbf{Q}$ was achieved based on a literature method using lead oxide and perchloric acid that has been applied to other calixarenes. ${ }^{14}$ The only variation from the literature method was additional dilution of the lead oxide/perchloric acid mixture with the organic solvent, which in our hands gave higher yields and a cleaner product for this particular system.

In addition to the usual suite of characterisation techniques, crystals of appropriate quality for a single crystal x-ray structure determination were obtained by slow evaporation of a methanol solution. The results of the structure determination were consistent with the formulation $\mathbf{Q} \cdot \mathrm{H}_{2} \mathrm{O}$ (Figure 2). The calixarene assumes a partial cone conformation. There are hydrogen bonds between the water molecule and the tetrazole rings and a quinone oxygen atom. There is also a hydrogen bond between the NH hydrogen and the other tetrazole group of the molecule related by a cell translation along the $b$-axis forming a 1-dimensional hydrogen bonded polymer. Hydrogen bonding geometrical details are listed in Table 1 with the hydrogen bonding polymer shown in Figure 3.

Table 1. Hydrogen bonds for $\mathbf{Q} \cdot \mathrm{H}_{2} \mathrm{O}\left[\AA\right.$ and $\left.{ }^{\circ}\right]$.

\begin{tabular}{lcccc}
\hline D-H...A & d(D-H) & d(H...A & $d($ D...A $)$ & $<($ DHA $)$ \\
\hline $\mathrm{N}(112)-\mathrm{H}(112) \ldots \mathrm{N}(312)^{1}$ & 0.88 & 1.94 & $2.778(5)$ & 159.3 \\
$\mathrm{~N}(315)-\mathrm{H}(315) \ldots \mathrm{O}(1)$ & 0.88 & 1.92 & $2.785(5)$ & 165.6 \\
$\mathrm{O}(1)-\mathrm{H}(1 \mathrm{AO}) \ldots \mathrm{O}(21)$ & $0.826(19)$ & $2.03(2)$ & $2.834(4)$ & $165(6)$ \\
$\mathrm{O}(1)-\mathrm{H}(1 \mathrm{BO}) \ldots \mathrm{N}(115)$ & $0.820(19)$ & $2.04(3)$ & $2.793(5)$ & $152(6)$ \\
\end{tabular}

Symmetry transformations used to generate equivalent atoms: ${ }^{1} \mathrm{x}, \mathrm{y}+1, \mathrm{z}$ 


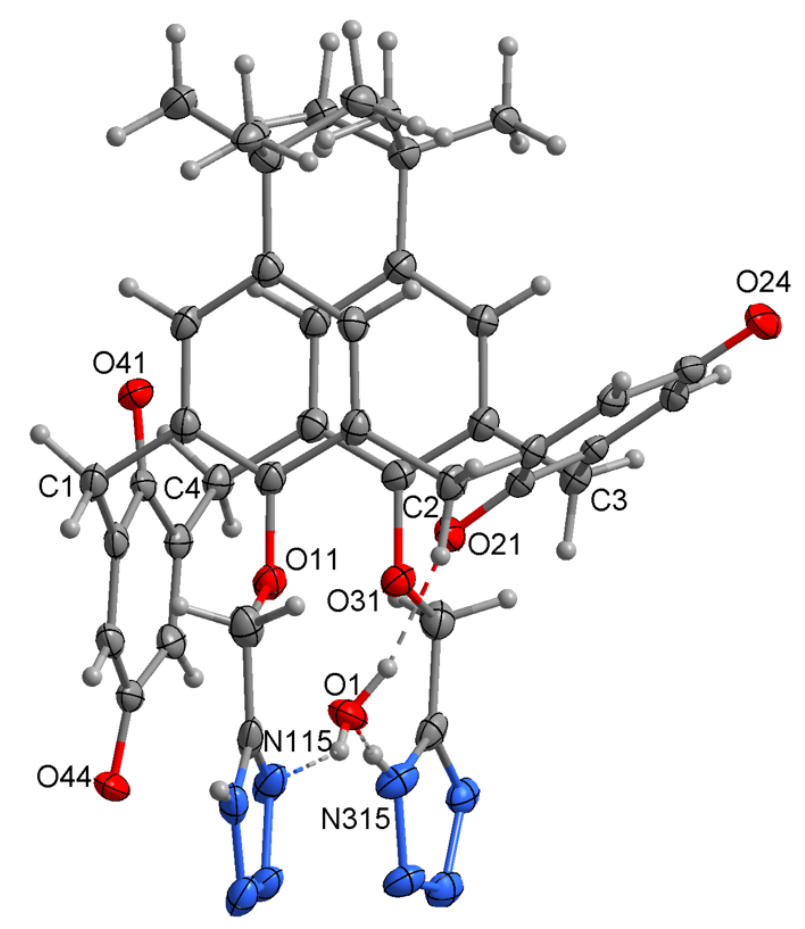

Figure 2 Structure of the molecule of $\mathbf{Q} \cdot \mathrm{H}_{2} \mathrm{O}$. One set of the disordered atoms has been omitted.

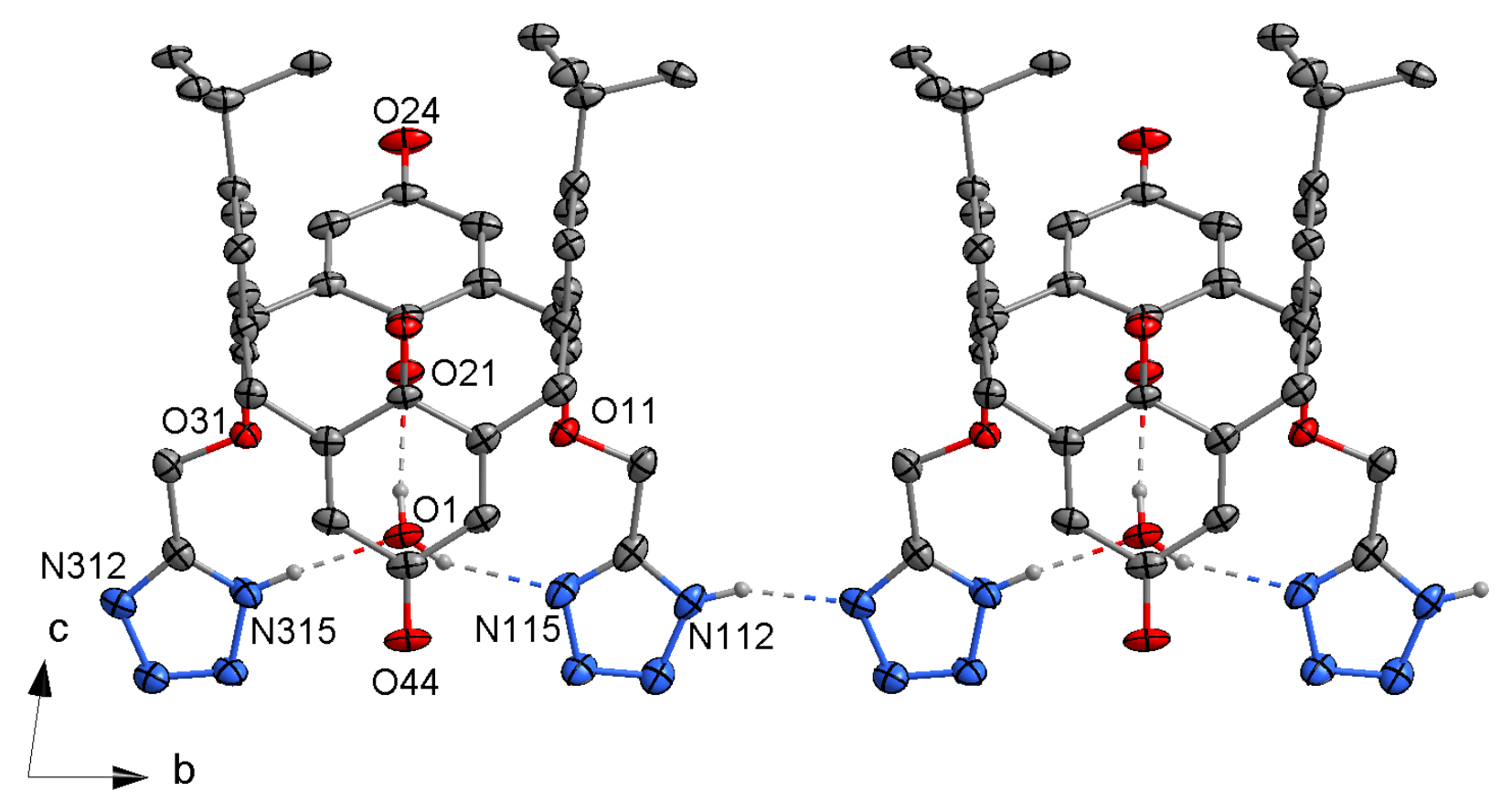

Figure 3 Structure of $\mathbf{Q} \cdot \mathrm{H}_{2} \mathrm{O}$ projected along the a-axis showing the hydrogen bonded polymer. Hydrogen atoms not involved in the hydrogen bonding and one set of the disordered atoms have been omitted.

The chemical reduction of quinone calixarenes has been reported using aqueous sodium dithionite, ${ }^{18}$ and sodium borohydride. ${ }^{19}$ Here we chose to use N,N-diethylhydroxylamine (DEH), which has been reported to reduced quinones, ${ }^{16}$ to reduce $\mathbf{Q}$ to the dihydroquinone $\mathbf{Q R}$, to simplify the isolation of the product. Changes in the NMR spectra of the product, consistent with a reduction in conformational mobility due to additional hydrogen bonding, were observed, with peak widths reducing and the methylene $\mathrm{AB}$ doublet separation increasing from 0.45 to $0.83 \mathrm{ppm}$. HRMS confirmed that the target 
had been isolated. With the ligands in hand, their complexation to lanthanoids was followed by studying their photophysical properties.

\section{Absorbance studies:}

The absorption of both ligands $(\mathbf{Q}$ and $\mathbf{Q R})$ were measured in ethanol with excess of triethylamine before and after the addition of excess of $\mathrm{Gd}^{3+}$ (Figure 4). Triethylamine was added to ensure the calixarene is deprotonated to maximise the stability of the lanthanoid-calixarene complex. ${ }^{15}$ The absorption profile of $\mathbf{Q}$ presents an intense band with maximum at $260 \mathrm{~nm}$ and a less intense but broader band in the 300-400 nm region. By comparison with the previously reported $p$ - $t$ butylcalix[4]arene functionalized at the lower rim with two tetrazole moieties, ${ }^{15}$ the first band can be assigned to a $\pi-\pi^{*}$ transition centred on tert-butyl substituted phenyl rings and some contribution from $\pi-\pi^{*}$ of the tetrazole rings, while the extra broad band centered at $340 \mathrm{~nm}$ can be attributed to the $\pi-\pi^{*}$ of quinone rings. On the other hand, the absorption spectrum of the reduced ligand (QR) shows a blue shift of both bands appearing now below $250 \mathrm{~nm}$ and $300 \mathrm{~nm}$, respectively. This blue shift may be caused by a more electron withdrawing effect coming from the phenolato ring in comparison to the quinone. When excess of the $\mathrm{GdCl}_{3} \cdot 6 \mathrm{H}_{2} \mathrm{O}$ was added in the same solution a clear red shift characteristic of efficient coordination was found in the case of $\mathbf{Q R}$, while no significant shift was observed in the case of the $\mathbf{Q}$. These data may suggest that coordination of the lanthanoid ions with ligand $\mathbf{Q}$ could be limited under the conditions tested.

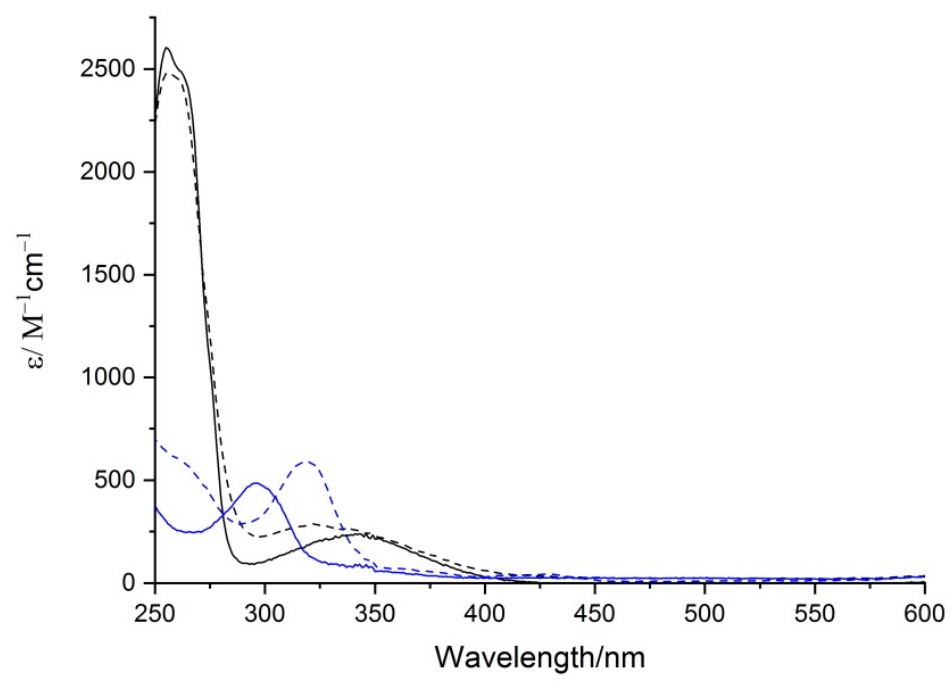

Figure 4. Absorption profiles of $\mathbf{Q}$ (black trace) and $\mathbf{Q R}$ (blue trace) in ethanol with excess of triethylamine in the presence (dotted trace) and absence (full trace) of excess of $\mathrm{GdCl}_{3} \cdot 6 \mathrm{H}_{2} \mathrm{O}$. 


\section{Photophysical Studies}

In order to assess if ligands $\mathbf{Q}$ and $\mathbf{Q R}$ can act as efficient antenna for the sensitisation of lanthanoids, the phosphorescent emission at $77 \mathrm{~K}$ of the corresponding $\mathrm{Gd}^{3+}$ was studied. Unfortunately, the triplet state estimated from the 0-phonon transition, could only be assigned for QR. In this case, both singlet and triplet states were observed at $30,300 \mathrm{~cm}^{-1}$ and $27,030 \mathrm{~cm}^{-1}$, respectively (Figure 5). This triplet excited state energy should be high enough to sensitize the ${ }^{5} \mathrm{D}_{4}$ of $\mathrm{Tb}^{3+}\left(\sim 20,400 \mathrm{~cm}^{-1}\right) \cdot{ }^{20}$ In contrast the results for $\mathbf{Q}$ do not seem to present a clear triplet emission band, which may indicate again limited coordination of the metal ion (Figure S1).

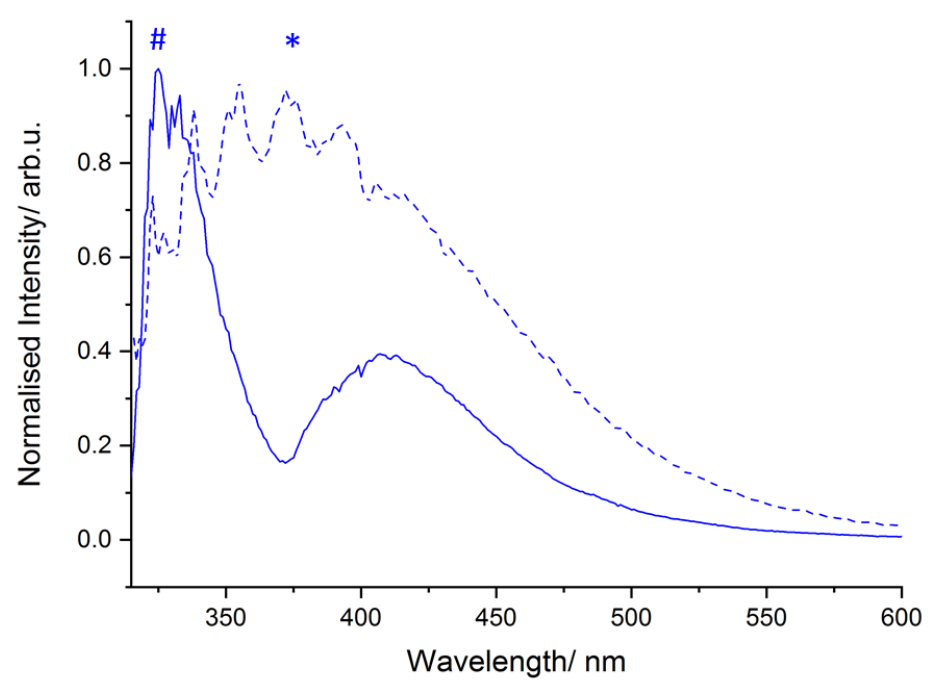

Figure 5. Emission $\left(\lambda_{\text {exc }}=300 \mathrm{~nm}\right.$ ) of ligand $\mathbf{Q R}$ (dark trace) and its $\mathrm{Gd}^{3+}$ complex (light trace) in ethanol at $77 \mathrm{~K}$. The \# and $*$ symbols indicates the 0 -phonon transition of the singlet and triplet excited states, respectively.

Emission of both ligands were then studied in the presence of excess of $\mathrm{Tb}^{3+}$ in ethanol at room temperature. In the case of $\mathbf{Q}$, no $\mathrm{Tb}^{3+}$ emission was observed and unexpectedly, only phosphorescence of the ligand could be seen (Figure S2). This could be explained by back energy transfer from the ${ }^{5} \mathrm{D}_{4}$ excited state of $\mathrm{Tb}^{3+}$ centered at $\sim 487 \mathrm{~nm}$, which lies relatively close to the apparent triplet state of $\mathbf{Q}$, which was able to be assigned as $\sim 21,300 \mathrm{~cm}^{-1}$ based on these data. Therefore, while these results suggest that $\mathbf{Q}$ does coordinate to $\mathrm{Tb}^{3+}$ to a sufficient degree to undergo back transfer, it is confirmed as a poor antenna ligand at least for this lanthanoid cation.

In contrast, $\mathbf{Q R}$ seems to sensitise more efficiently the ${ }^{5} \mathrm{D}_{4}$ of $\mathrm{Tb}^{3+}$ based on the presence of the linelike bands from the ${ }^{5} \mathrm{D}_{4} \rightarrow{ }^{7} \mathrm{~F}_{\mathrm{J}}(\mathrm{J}=6,5,4,3)$ transition (Figure 6). The broad excitation spectrum found with emission wavelength at the main emission peak of $\mathrm{Tb}^{3+}(540 \mathrm{~nm})$ suggests an efficient energy transfer whereas direct excitation of the $\mathrm{Tb}^{3+}$ excited states can be omitted. Indeed, when 
compared with the excitation spectrum of the $\mathrm{TbCl}_{3}$ employed for these studies a clear difference in shape of the excitation spectra can be observed. However, the baseline of the emission profile is not flat, which indicates possible emission of the ligand simultaneously occurring. The excited state lifetime $(\tau)$ found at $540 \mathrm{~nm}$ was fitted to a biexponential decay with $\tau=134 \mu \mathrm{s}(30 \%)+42 \mu \mathrm{s}(70 \%)$, which is consistent with emission from two different species.

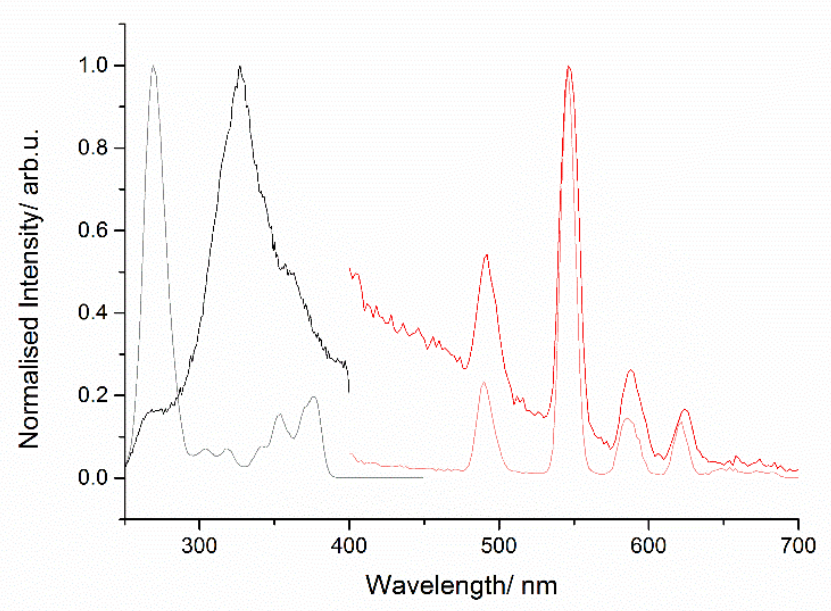

Figure 6. Normalised excitation $\left(\lambda_{\mathrm{em}}=540 \mathrm{~nm}\right)$ (black trace) and emission $\left(\lambda_{\mathrm{exc}}=300 \mathrm{~nm}\right)$ (red trace) plots for QR in the presence of excess of $\mathrm{TbCl}_{3}$ (dark trace) and $\mathrm{TbCl}_{3}$ (light trace) in $\mathrm{EtOH}\left(\mathrm{ca} .10^{-5} \mathrm{M}\right)$.

\section{Conclusions}

The work presented here confirms that the photophysical response of a lanthanoid - calixquinone antenna assembly can be changed by reducing the molecule to the dihydroquinone analogue, where the response is a switching on of the lanthanoid emission in the case of terbium. Further work will be required to determine the relative influence of the change in the spectroscopic properties of the antenna, and the change in the binding efficacy of the ionophore.

\section{Acknowledgements}

We acknowledge the ECU Science Analytical Facility/ Thermo-Fisher Proof of Concept Laboratory for the HRMS measurements.

\section{References}

1. Vataj, R.; Louati, A.; Jeunesse, C.; Matt, D., Electrochem. Commun. 2000, 2 (11), 769-775. 
2. Leontiev, A. V.; Serpell, C. J.; White, N. G.; Beer, P. D., Chem. Sci. 2011, 2 (5), 922-927.

3. Picot, S. C.; Mullaney, B. R.; Beer, P. D., Chem. Eur. J. 2012, 18 (20), 6230-6237.

4. Webber, P. R. A.; Chen, G. Z.; Drew, M. G. B.; Beer, P. D., Angew. Chem. Int. Edit. 2001, 40 (12), 2265-2268.

5. Webber, P. R. A.; Beer, P. D.; Chen, G. Z.; Felix, V.; Drew, M. G. B., J. Am. Chem. Soc. 2003, 125 (19), 5774-5785.

6. Beer, P. D.; Gale, P. A.; Chen, Z.; Drew, M. G. B.; Heath, J. A.; Ogden, M. I.; Powell, H. R., Inorg. Chem. 1997, 36 (25), 5880-5893.

7. Beer, P. D.; Chen, Z.; Gale, P. A.; Heath, J. A.; Knubley, R. J.; Ogden, M. I.; Drew, M. G. B., J. Inclusion Phenom. Mol. Recognit. Chem. 1994, 19 (1), 343-359.

8. Lankshear, M. D.; Cowley, A. R.; Beer, P. D., Chem. Commun. 2006, (6), 612-614.

9. Lankshear, M. D.; Dudley, I. M.; Chan, K. M.; Cowley, A. R.; Santos, S. M.; Fejix, V.; Beer, P. D., Chem. Eur. J. 2008, 14 (7), 2248-2263.

10. Knighton, R. C.; Beer, P. D., Chem. Commun. 2014, 50 (13), 1540-1542.

11. Kang, S. K.; Lee, O. S.; Chang, S. K.; Chung, D. S.; Kim, H.; Chung, T. D., J Phys Chem C 2009, 113 (46), 19981-19985.

12. Huang, C.; Zhang, X.; Li, G.; Jiang, Y.; Wang, Q.; Tian, R., Hum. Exp. Toxicol. 2014, 33 (5), 554-558.

13. Lin, Y.-L.; Yu, T.-S.; Wang, W.-Y.; Lin, L.-G., Tetrahedron 2006, 62 (25), 6082-6089.

14. Lavendomme, R.; Troian-Gautier, L.; Zahim, S.; Reinaud, O.; Jabin, I., Eur. J. Org. Chem. 2016, 2016 (9), 1665-1668.

15. D’Alessio, D.; Muzzioli, S.; Skelton, B. W.; Stagni, S.; Massi, M.; Ogden, M. I., Dalton Trans. 2012, 41 (16), 4736-4739.

16. Fujita, S.; Sano, K., J. Org. Chem. 1979, 44 (15), 2647-2651.

17. Sheldrick, G. M., Acta Crystallogr. Sect. C: Struct. Chem. 2015, 71, 3-8.

18. Genorio, B., Acta Chim. Slov. 2016, 63 (3), 496-508.

19. Meddeb-Limem, S.; Malezieux, B.; Herson, P.; Besbes-Hentati, S.; Said, H.; Blais, J. C.; Bouvet, M., J. Phys. Org. Chem. 2005, 18 (12), 1176-1182.

20. McCaw, C. S.; Murdoch, K. M.; Denning, R. G., Mol. Phys. 2003, 101 (3), 427-438. 


\section{Lanthanoid Coordination with a Tetrazole-Substituted Calix[4]diquinone and Calix[4]dihydroquinone}

Lee Cameron, Aswin Rajagopalan, Laura Abad Galan, Rene Z.H, Phe, Brian W. Skelton, Massimiliano Massi, and Mark I. Ogden

Supplementary Information

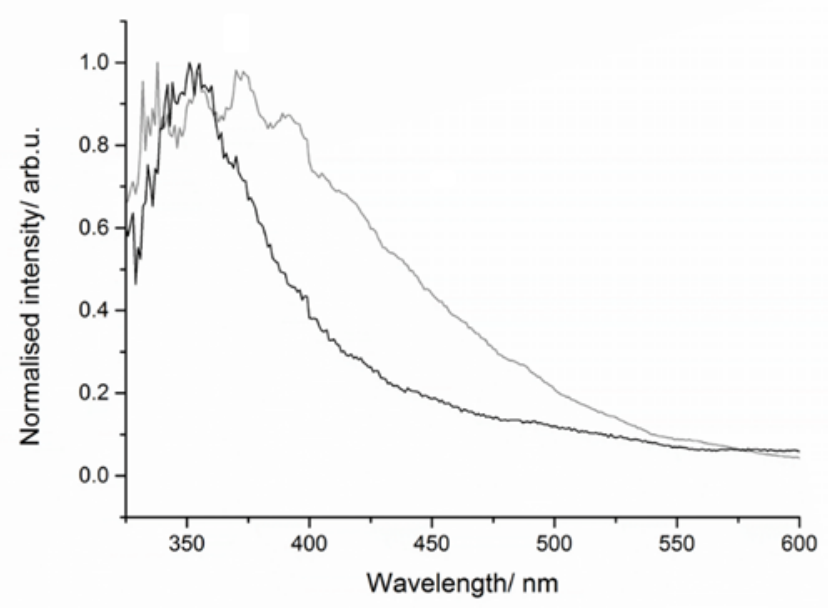

Figure S1.Normalised emission $\left(\lambda_{\text {exc }}=300 \mathrm{~nm}\right.$ ) of ligand $\mathbf{Q}$ (dark trace) and its $\mathrm{Gd}^{3+}$ complex (light trace) in ethanol at $77 \mathrm{~K}$.

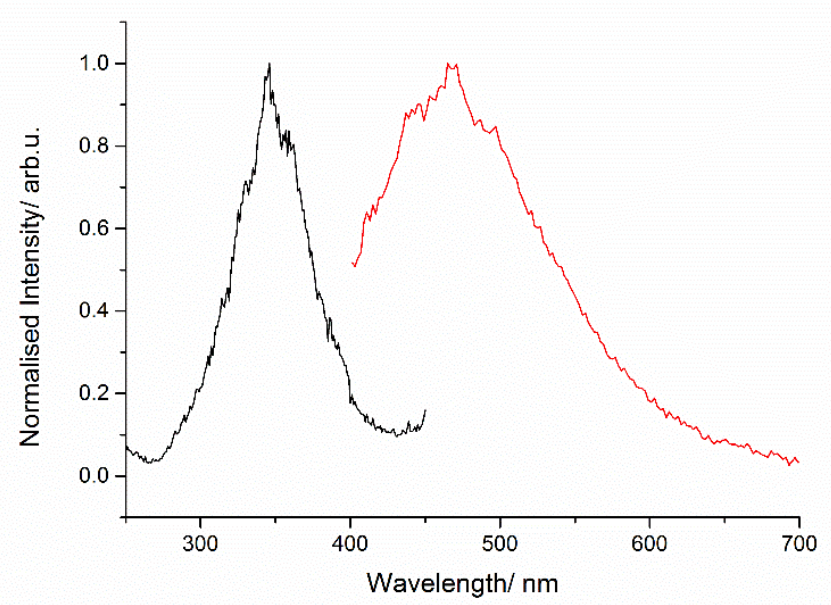

Figure S2. Normalised excitation $\left(\lambda_{\mathrm{em}}=485 \mathrm{~nm}\right)$ and emission $\left(\lambda_{\mathrm{exc}}=300 \mathrm{~nm}\right)$ plot for $\mathbf{Q}$ in the presence of excess of $\mathrm{TbCl}_{3}$ in $\mathrm{EtOH}\left(\right.$ ca. $\left.10^{-5} \mathrm{M}\right)$. 